\title{
Budget impact of switching from an immediate- release to a prolonged-release formulation of tacrolimus in renal transplant recipients in the UK based on differences in adherence
}

\author{
This article was published in the following Dove Press journal: \\ Patient Preference and Adherence \\ 28 March 2014 \\ Number of times this article has been viewed
}

\section{Gorden Muduma' \\ Isaac Odeyemi' \\ Jayne Smith-Palmer ${ }^{2}$ \\ Richard F Pollock ${ }^{2}$}

'Astellas Pharma Europe, Chertsey, UK; ${ }^{2}$ Ossian Health Economics and

Communications, Basel, Switzerland
Correspondence: Richard F Pollock

Ossian Health Economics and

Communications, 20 Bäumleingasse,

Basel 405I, Switzerland

Tel+4I6I 27| 62I4

Email pollock@ossianconsulting.com
Background and aims: Advagraf is a once-daily prolonged-release formulation of tacrolimus with proven noninferiority to Prograf, a twice-daily immediate-release formulation of tacrolimus, in biopsy-proven acute rejection, graft survival and patient survival in renal transplant recipients. Advagraf is associated with improved adherence compared with Prograf, which may ultimately improve long-term outcomes. The present study assessed the budget impact of switching patients from Prograf to Advagraf in the UK.

Materials and methods: A budget-impact model was constructed based on published data on acute rejection, graft failure, and mortality in the UK setting. Patients were assumed to convert from Prograf to Advagraf on a 1:1 milligram:milligram basis. In a study comparing the adherence rates between once-daily versus twice-daily formulations of tacrolimus, the proportion of patients taking the prescribed number of daily doses was $88.2 \%$ in Advagraf patients and $78.8 \%$ in Prograf patients. The model applied a relative risk of graft failure of 3.47 to nonadherent patients based on data from a 2004 meta-analysis (based on graft-failure rates of $1.3 \%-40.0 \%$ in adherent patients, compared with $6.1 \%-100 \%$ in nonadherent patients). Cost data were taken from the March 2013 British National Formulary and 2012-2013 National Health Service tariff information. The analysis was performed over a 5-year time horizon and future costs were not discounted, in line with International Society for Pharmacoeconomics and Outcomes Research guidelines.

Results: Over a 5-year time horizon, the mean cost per patient (including tacrolimus, concomitant immunosuppressive medications, dialysis after graft failure, and treatment for acute rejection) was $£ 29,328$ (standard deviation [SD] £2,844) for Advagraf versus £33,061 (SD £3,178) for Prograf. The total cost saving of $£ 3,733$ (SD $£ 530$ ) was driven primarily by reduced dialysis costs arising from the lower incidence of graft failure (21.6\% with Prograf versus $18.3 \%$ with Advagraf) in the larger proportion of adherent patients in the Advagraf arm. In a hypothetical transplant centre of 100 kidney-transplant recipients, this would result in cost savings approaching $£ 375,000$ over 5 years.

Conclusion: Conversion of renal transplant recipients from Prograf to Advagraf was associated with lower pharmacy and dialysis costs, with the reduction in dialysis costs being driven by improved adherence to Advagraf regimen and the consequent improvement in graft survival.

Keywords: tacrolimus, patient adherence, costs and cost analysis, Great Britain

\section{Introduction}

Tacrolimus is a potent macrolide immunosuppressive agent that is highly effective in the prophylaxis of transplant rejection and in the treatment of allograft rejection in 
patients resistant to treatment with other immunosuppressive agents. ${ }^{1}$ Initially approved by the Food and Drug Administration (FDA) in 1994 for the prophylaxis of graft rejection after liver transplantation, tacrolimus is currently indicated for rejection prophylaxis in kidney and liver allograft recipients in the EU. ${ }^{2,3}$ In adult patients, tacrolimus has typically been prescribed as a twice-daily capsule with a starting dose of $0.2-0.3 \mathrm{mg} / \mathrm{kg} /$ day in kidney transplant recipients. ${ }^{3}$

Given the proven effectiveness of tacrolimus in preventing posttransplantation graft rejection, patient adherence to the prescribed regimen becomes a critical factor in improving graft-survival outcomes. A 2007 meta-analysis reported that the risk of nonadherence to immunosuppressive regimens was highest in renal transplant recipients. ${ }^{4}$ Several studies have since reported on various factors that can influence adherence in transplant recipients, including a 2012 study, which showed that there is a strong inverse association between the number of immunosuppressive medications used by a transplant recipient and the proportion of patients who are adherent to therapy. ${ }^{5}$ Furthermore, dosing frequency and regimen complexity have also been associated with reduced adherence. ${ }^{6}$ Given that twice-daily, immediate-release formulations still constitute the majority of UK immunosuppressant prescriptions, there is still a great unmet need in allograft recipients for reduced pill burden. ${ }^{7}$

In April 2007, the European Commission granted EUwide marketing authorization for Advagraf, a once-daily, prolonged-release formulation of tacrolimus. The topic of patient adherence was addressed in the public summary of the European public assessment report for Advagraf, which noted that the once-daily formulation "can help patients stick to their treatment" (ie, improve adherence). ${ }^{8}$ The report statement is closely aligned with results of previous studies demonstrating that once- versus twice-daily dosing can lead to greater adherence to the prescribed regimen. ${ }^{6,9,10}$ In the specific case of Advagraf and Prograf, a 2013 randomized controlled study reported that the proportion of patients who are adherent to the prescribed regimen is $88.2 \%$ and $78.8 \%$ respectively, corroborating the inverse relationship between dose frequency and adherence in renal transplant recipients. $^{11}$

Numerous studies have reported that suboptimal adherence to immunosuppressive treatment can increase the risk of late acute rejection and graft loss. ${ }^{12-14}$ For instance, a 2004 meta-analysis was conducted into the frequency and effect of nonadherence to immunosuppressive regimens in renal transplant recipients. The study found that the odds of graft failure in nonadherent patients were 7.1 higher than in patients adherent to therapy. ${ }^{15}$ Of the studies included in the meta-analysis, the most common definition of nonadherence was missing, forgetting, or altering a dose at least once per month. More recently, a 2009 study into patient adherence to immunosuppressive regimens after renal transplant divided patients into quartiles based on their medication-possession ratio (MPR) and analyzed the incidence of graft failure in each quartile. ${ }^{13}$ The upper MPR quartile boundaries over the course of the study were $0.811,0.951$, and 0.998 for the first, second, and third quartiles in ascending order of adherence. Compared with patients in the highest-adherence quartile (described as "excellent" adherence in the study), patients in the third ("fair") and lowest ("poor") quartiles had increased risk of graft failure, with Cox proportional hazard ratios of 1.63 and 1.80, respectively. Among survivors at year 1, graft failure in the subsequent 2 years was $11.5 \%$ in the "poor" compliance group relative to $7.4 \%$ in the "excellent" compliance group $(P<0.0001)$. Similarly, a 2014 study by Spivey et al found a significant association between higher MPR and reduced graft-failure risk in a retrospective analysis of 31,913 renal transplant patients in the US Renal Data System. ${ }^{14}$

Based on these data on differences in adherence between Prograf and Advagraf and the reported increase in graftfailure risk in nonadherent patients, the present study aimed to evaluate the budgetary implications of switching renal transplant recipients from an immediate-release tacrolimus formulation to prolonged-release tacrolimus from the perspective of a health care payer in the UK setting.

\section{Materials and methods Model}

A budget-impact model was constructed in Microsoft Excel to evaluate the costs associated with using prolonged-release tacrolimus (Advagraf) relative to immediate-release tacrolimus (Prograf) in patients undergoing de novo kidney transplant in the UK setting. The model was designed to capture the clinical end points of graft failure, acute rejection, and patient mortality. The underlying incidence of graft failure and patient mortality was based on data from the 2011-2012 National Health Service Blood and Transplant (NHSBT) organ-donation and transplantation-activity report. ${ }^{16}$ Specifically, data on the proportion of grafts and patients surviving at years 1,2, and 5 after first kidney transplant from donors after brain death were taken from 2,469 UK patients having undergone transplantation in 2004-2006. Graft and patient survival in years 3 and 4 were linearly interpolated using the data at years 2 and 5 (Figure 1). As the incidence of acute rejection was not reported in the NHSBT annual 


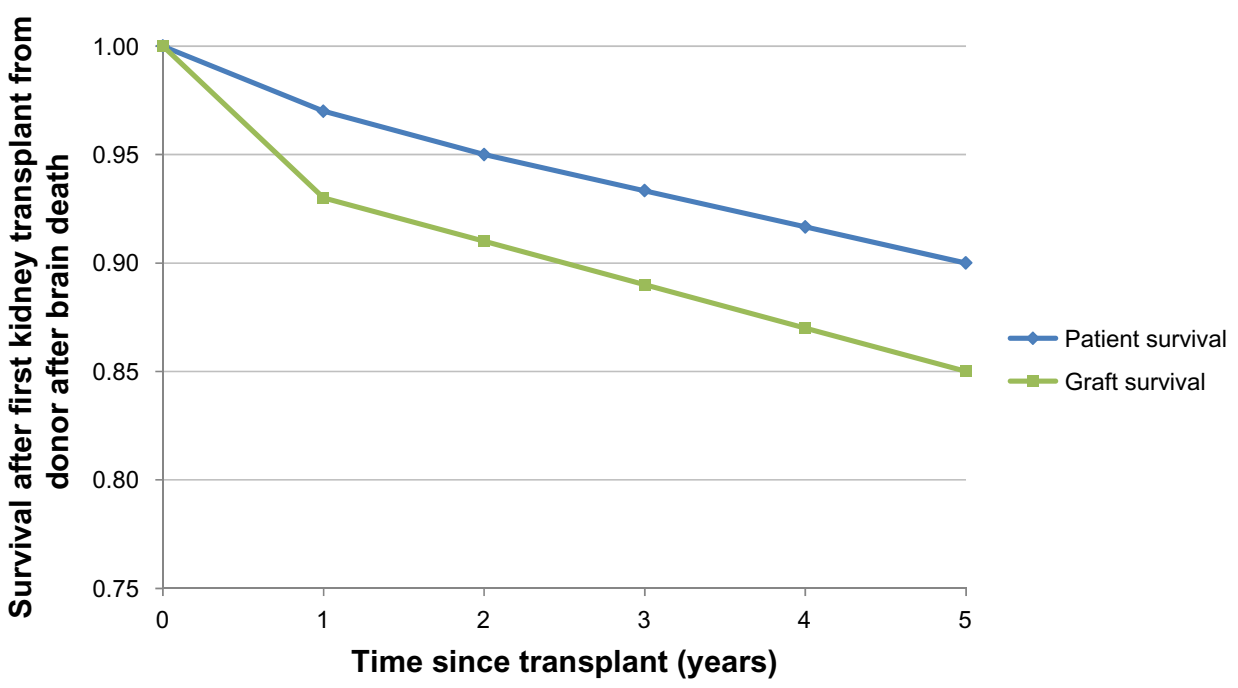

Figure I Graft and patient survival from the National Health Service Blood and Transplant 20I I-20I2 organ-donation and transplantation-activity report. ${ }^{16}$ Note: Data at years 3 and 4 were linearly interpolated using values from years 2 and 5.

report, data on acute rejection were taken from a 2006 UK database analysis by McEwan et al. ${ }^{17}$

The cohort was assumed to have a mean body weight of $70.3 \mathrm{~kg}$, based on a multicenter randomized trial of Advagraf and Prograf in 667 de novo renal transplant recipients published in 2010 by Krämer et al. ${ }^{18}$ The model used mean body weight to calculate the mean daily dose of tacrolimus and the concomitant medications mycophenolate mofetil (MMF) and corticosteroids (betamethasone) based on data from the Krämer et al study. In the case of tacrolimus, the doses in the Advagraf and Prograf arms were based on the dose at study day $365(0.075 \mathrm{mg} / \mathrm{kg} /$ day $)$ and were taken to be equivalent, since patients in the Krämer et al study were initiated on the same dose (of $0.2 \mathrm{mg} / \mathrm{kg} /$ day) and subsequent differences (arising from titration to a prespecified serum trough concentration) were not reported as significant. In the base case, mean MMF doses were taken to be $1,450 \mathrm{mg}$ / day in year 1 (based on the mean of the doses at baseline and day 365) and $960 \mathrm{mg} /$ day in subsequent years (based on the dose at day 365 in the Krämer et al study). All patients were assumed to continue taking MMF for the duration of the modeling analysis. Corticosteroid doses were calculated on the same basis as MMF, and were $16.6 \mathrm{mg}$ /day in year 1 and $4.9 \mathrm{mg} /$ day in subsequent years. However, in contrast to MMF, the proportion of patients taking corticosteroids was taken to be $94.7 \%$ in the first year, dropping to $89.3 \%$ in subsequent years, also based on the Krämer et al study. ${ }^{18}$

The proportion of patients remaining adherent to their immunosuppressive regimen and the effects of adherence on graft failure risk were modeled using data from two studies. The first was a 9-month randomized controlled trial (consisting of a 3-month run-in and a 6-month follow-up period after randomization) that evaluated adherence to the prescribed regimen in 219 patients taking Prograf and Advagraf. ${ }^{11}$ In brief, the study defined the proportion of adherent patients as the proportion of patients who dosed at least the prescribed dose on a day-to-day basis, expressed as a percentage of the number of patients still engaged with the treatment, as measured using an electronic monitor. Longitudinal logistic models were then used to indicate whether patients in each arm took a given day's dose or not. The study found that $88.2 \%$ of patients on Advagraf remained engaged with the regimen, compared with $78.8 \%$ on Prograf. Data from the second study, a 2004 meta-analysis by Butler et al was used to expose nonadherent patients (11.8\% and $21.2 \%$ for Advagraf and Prograf, respectively) to an increased risk of graft failure..$^{15}$ According to the study, the odds of graft failure in nonadherent subjects were 7.1-fold greater than in adherent patients (95\% confidence interval 4.4-11.7). For the purposes of the modeling analysis, this was converted to a relative risk of 3.47 using the Zhang and Yu method. ${ }^{19}$

In the base-case analysis, the model assumed that patients experiencing graft failure all started dialysis (rather than undergoing kidney retransplantation). Based on the midpoint of estimates from the National Institute for Health and Care Excellence (NICE) clinical guideline on peritoneal dialysis, ${ }^{20}$ $15 \%$ of patients were assumed to be on peritoneal dialysis, with the remaining $85 \%$ undergoing hemodialysis. Of those patients on hemodialysis, all were assumed to have three dialysis sessions per week, based on the Renal Association hemodialysis guidelines. ${ }^{21}$ 
While the model was constructed to allow different risks of acute rejection and mortality to be applied to patients on Advagraf and Prograf, the relative risks were set to 1 in both arms in the base-case analysis. The incidence of acute rejection and mortality was therefore equivalent in both arms.

\section{Costs}

All pharmacy cost data were taken from the March 2013 British National Formulary (BNF), while dialysis costs were taken from the 2012-2013 NHS tariff information (Table 1). ${ }^{22-29}$ Costs associated with an acute rejection episode were based on the assumption that patients would have 3 days of intravenous methylprednisolone therapy at $250 \mathrm{mg} /$ day, while rejection episodes refractory to such treatment would be treated with a 10-day intravenous infusion of antithymocyte globulin at $1.5 \mathrm{mg} / \mathrm{kg} /$ day.

\section{Perspective, time horizon, and discounting}

The base-case analysis was conducted over a 5-year time horizon and outcomes were not discounted, in line with budget-impact modeling guidance from the International Society for Pharmacoeconomics and Outcomes Research. ${ }^{30}$ However, sensitivity analyses were performed in which the discount rate was set to $3.5 \%$, in line with the recommendations for discounting the cost component of cost-effectiveness analyses laid out in the NICE guide to the methods of technology appraisal. ${ }^{31}$ All analyses were performed from the perspective of a UK health care payer.

\section{Sensitivity analyses}

A series of sensitivity analyses were conducted around the base case to establish the magnitude of effect of various drivers on the absolute and incremental outcomes. Analyses were

Table I Costs used in the base-case analysis

\begin{tabular}{|c|c|c|}
\hline Cost item & Cost (t/mg) & Reference \\
\hline Advagraf & 1.43 & $\mathrm{BNF}^{22}$ \\
\hline Prograf & 1.61 & $\mathrm{BNF}^{23}$ \\
\hline Adoport (generic tacrolimus) & 1.31 & $\mathrm{BNF}^{24}$ \\
\hline Mycophenolate mofetil & 0.00126 & $\mathrm{BNF}^{25}$ \\
\hline Corticosteroids & 0.164 & $\mathrm{BNF}^{26}$ \\
\hline Cost item & Cost & Reference \\
\hline Acute rejection episode $(t)$ & 28.5 & $\mathrm{BNF}^{27}$ \\
\hline $\begin{array}{l}\text { Treatment-refractory acute } \\
\text { rejection episode }(€)\end{array}$ & $6,701.65$ & $\mathrm{BNF}^{28}$ \\
\hline Peritoneal dialysis ( $\epsilon /$ day) & 53.00 & $\begin{array}{l}\text { NHS National Tariff } \\
(\text { HRG LDI2A) })^{29}\end{array}$ \\
\hline Hemodialysis ( $£$ /session) & 123.00 & $\begin{array}{l}\text { NHS National Tariff } \\
(\text { HRG LDOIA })^{29}\end{array}$ \\
\hline
\end{tabular}

Abbreviations: BNF, British National Formulary; HRG, Healthcare Resource Group; NHS, National Health Service. performed in which the discount rate was set to $3.5 \%$ and the time horizon changed to 3 years. The effect of a proportion of graft-failure patients undergoing retransplantation rather than dialysis was also explored in an analysis utilizing retransplantation incidence data from the McEwan et al database analysis. ${ }^{17}$ In the retransplantation sensitivity analysis, patients not undergoing retransplantation underwent dialysis in line with base-case proportions of $15 \%$ peritoneal dialysis and $85 \%$ hemodialysis. The cost of kidney retransplantation, which does not have an associated Healthcare Resource Group code, was taken to be $£ 22,080$, based on a 2011 UK cost-effectiveness analysis that reported kidneytransplantation costs. ${ }^{32}$

Four analyses were performed around the relative risk of graft failure in nonadherent patients compared with adherent patients. Two of the relative-risk analyses were based on data from a 2009 study by Pinsky et al, in which the relative risks of graft failure were taken from patients categorized as having "fair" and "poor" adherence (based on their adherence quartile within the whole study population), with relative risks of 1.63 and 1.8 compared with the "excellent" group, respectively. ${ }^{13}$ An additional analysis was then performed based on data from a 2012 study by Sellarés et al, in which 19 of 26 nonadherent patients experienced graft failure, compared with 41 of 289 adherent patients, giving a relative risk of $5.15 .{ }^{33} \mathrm{~A}$ final relative-risk sensitivity analysis was conducted, in which the model assumed no difference in the relative risk of graft failure in adherent and nonadherent patients. Two cost sensitivity analyses were then run, in which the cost of Prograf was set to be equivalent to that of Advagraf and subsequently to be equivalent to that of Adoport, a generic tacrolimus formulation (Table 1).

In addition to the individual one-way sensitivity analyses, a series of five analyses were performed to establish the relationship between relative risk of graft failure in nonadherent patients and the incremental cost of Advagraf relative to Prograf. In this analysis, the relative risk of graft failure with nonadherence was varied linearly between 1 (no change in risk) and 3.47 (the base-case value).

To obtain measures of variance around the modeled outcomes, probabilistic sensitivity analysis was conducted around the base case and all one-way sensitivity analyses. In each analysis, the model performed 10,000 iterations, with each iteration sampling from distributions around key model parameters. Normal distributions around body weight and tacrolimus, MMF, and corticosteroid dosing were sampled based on data from the Krämer et al clinical trial, and a uniform distribution of the proportion of graft failure patients 
undergoing peritoneal dialysis ( $0 \%-30 \%)$ and hemodialysis (70\%-100\%) was sampled based on the range provided in NICE Clinical Guideline 125, assuming that peritoneal and hemodialysis are the only dialysis modalities used in the UK setting. ${ }^{18,20}$ Finally, a lognormal distribution around the converted odds ratio of graft failure in adherent versus nonadherent patients was sampled based on the confidence intervals reported in the Butler et al meta-analysis. ${ }^{15}$ All results were reported as mean cost and standard deviation (SD) in each arm, and the mean and SD incremental cost.

\section{Results}

The base-case analysis (assuming the maximum relative risk of graft failure with nonadherence) showed that patients treated with Advagraf incurred costs of $£ 29,328$ (SD £2,844) over 5 years, compared with £33,061 (SD $£ 3,178$ ) in patients treated with Prograf, representing a saving of $£ 3,733$ (SD $£ 530$ ) per patient or $£ 373,300$ (SD $£ 53,000)$ in a hypothetical 100-patient transplant center (Table 2). Cost savings were driven primarily by a reduction in the projected proportion of patients experiencing graft failure over 5 years from $21.6 \%$ with Prograf to $18.3 \%$ with Advagraf. This was driven by the greater proportion of patients in the Advagraf arm adherent to their immunosuppressive regimen $(88.2 \%$ relative to $78.8 \%)$. In the first year of the analysis, cost savings of $£ 622$ (SD £106) per patient were realized, which would translate to first-year savings of $£ 62,200$ in a 100-patient transplant center. The basecase assumptions were such that there were no differences in mortality, incidence of acute rejection, or concomitant medication costs.

As anticipated, shortening the model time horizon lowered the cost savings with Advagraf: cost savings over 3 years were $£ 2,065$ (SD £311) per patient (Table 3 ). Increasing the discount rate to $3.5 \%$ reduced the cost

Table 2 Base-case results expressed as per-patient costs over a 5 -year time horizon

\begin{tabular}{|c|c|c|c|}
\hline & $\begin{array}{l}\text { Advagraf } \\
(t)\end{array}$ & $\begin{array}{l}\text { Prograf } \\
(\epsilon)\end{array}$ & $\begin{array}{l}\text { Difference } \\
(t)\end{array}$ \\
\hline $\begin{array}{l}\text { Cost of tacrolimus } \\
\text { treatment }\end{array}$ & $12,910 \pm 2,767$ & $14,467 \pm 3,098$ & $-1,557 \pm 519$ \\
\hline $\begin{array}{l}\text { Cost of concomitant } \\
\text { medications }\end{array}$ & $4,182 \pm 543$ & $4,182 \pm 543$ & $0 \pm 0$ \\
\hline Cost of dialysis & $12,112 \pm 119$ & $|4,288 \pm 2| 3$ & $-2,176 \pm 94$ \\
\hline $\begin{array}{l}\text { Cost of acute } \\
\text { rejection }\end{array}$ & $125 \pm 0$ & $125 \pm 0$ & $0 \pm 0$ \\
\hline Total & $29,328 \pm 2,844$ & $33,061 \pm 3,178$ & $-3,733 \pm 530$ \\
\hline
\end{tabular}

Note: Results presented as means \pm standard deviation.
Table 3 One-way sensitivity-analysis results

\begin{tabular}{|c|c|c|c|}
\hline & $\begin{array}{l}\text { Advagraf } \\
(t)\end{array}$ & $\begin{array}{l}\text { Prograf } \\
(E)\end{array}$ & $\begin{array}{l}\text { Difference } \\
(\epsilon)\end{array}$ \\
\hline Base case & $29,328 \pm 2,844$ & $33,061 \pm 3,178$ & $-3,733 \pm 530$ \\
\hline 3-year time horizon & $17,054 \pm 1,679$ & $|9| 19 \pm,|, 87|$ & $-2,065 \pm 311$ \\
\hline $3.5 \%$ discount rate & $27,463 \pm 2,552$ & $30,949 \pm 2,864$ & $-3,485 \pm 496$ \\
\hline With retransplantation & $26,04 I \pm 2,663$ & $29,200 \pm 2,994$ & $-3,159 \pm 523$ \\
\hline $\begin{array}{l}\text { No difference in } \\
\text { graft failure RR with } \\
\text { nonadherence }\end{array}$ & $26,640 \pm 2,722$ & $28,222 \pm 3,043$ & $-1,582 \pm 522$ \\
\hline $\begin{array}{l}\text { "Fair" adherence } \\
\text { RR from Pinsky et al' }\end{array}$ & $27,080 \pm 2,944$ & $29,174 \pm 3,270$ & $-2,094 \pm 520$ \\
\hline $\begin{array}{l}\text { "Poor" adherence } \\
\text { RR from Pinsky et al' }\end{array}$ & $27,472 \pm 2,752$ & $29,757 \pm 3,077$ & $-2,285 \pm 5 \mid 5$ \\
\hline $\begin{array}{l}\text { Graft failure RR from } \\
\text { Sellarés et a }\left.\right|^{28}\end{array}$ & $3 \mid, 021 \pm 2,766$ & $36,227 \pm 3,114$ & $-5,207 \pm 535$ \\
\hline $\begin{array}{l}\text { No difference in cost } \\
\text { of Advagraf and Prograf }\end{array}$ & $30,860 \pm 3,081$ & $33,061 \pm 3,178$ & $-2,201 \pm 432$ \\
\hline $\begin{array}{l}\text { Prograf cost-equivalence } \\
\text { with Adoport }\end{array}$ & $29,328 \pm 2,844$ & $30,372 \pm 2,552$ & $-I, 044(440)$ \\
\hline
\end{tabular}

Note: Results presented as mean \pm standard deviation. Abbreviation: $R R$, relative risk.

savings with Advagraf to $£ 3,485$ (SD £496) per patient. In the retransplantation analysis (in which a proportion of graft-failure patients undergo retransplantation instead of dialysis based on UK-specific retransplantation data from McEwan et al), the cost savings with Advagraf relative to Prograf decreased to $£ 3,159$ (SD £523). ${ }^{17}$ The two analyses in which the relative risk of graft failure was taken from the Pinsky et al study resulted in savings of $£ 2,094$ (SD £520) and $£ 2,285$ (SD $£ 515$ ) for the relative risks of graft failure in patients with "fair" and "poor" adherence, respectively. ${ }^{13}$ The higher relative risk of graft failure with nonadherence from the Sellarés et al study resulted in modeled savings of $£ 5,207$ (SD £535) per patient over the 5-year time horizon, corresponding to a saving of $£ 520,700$ in a hypothetical 100-patient transplant center. ${ }^{33}$ The cost sensitivity analysis, in which the per-milligram cost of Prograf was set to cost equivalence with Advagraf, still resulted in cost savings in the Advagraf arm of $£ 2,201$ (SD $£ 432$ ). Similarly, changing the per-milligram cost of Prograf to cost equivalence with Adoport resulted in savings in the Advagraf arm of $£ 1,044$ (SD £440). These would correspond to average savings of $£ 220,100$ and $£ 104,400$ over 5 years in a 100 -patient transplant center, respectively.

Finally, the analysis in which the relative risk of graft failure with nonadherence was varied between 1 and 3.47 showed a linear relationship between the relative risk and the incremental cost savings with Advagraf relative to Prograf (Figure 2). 


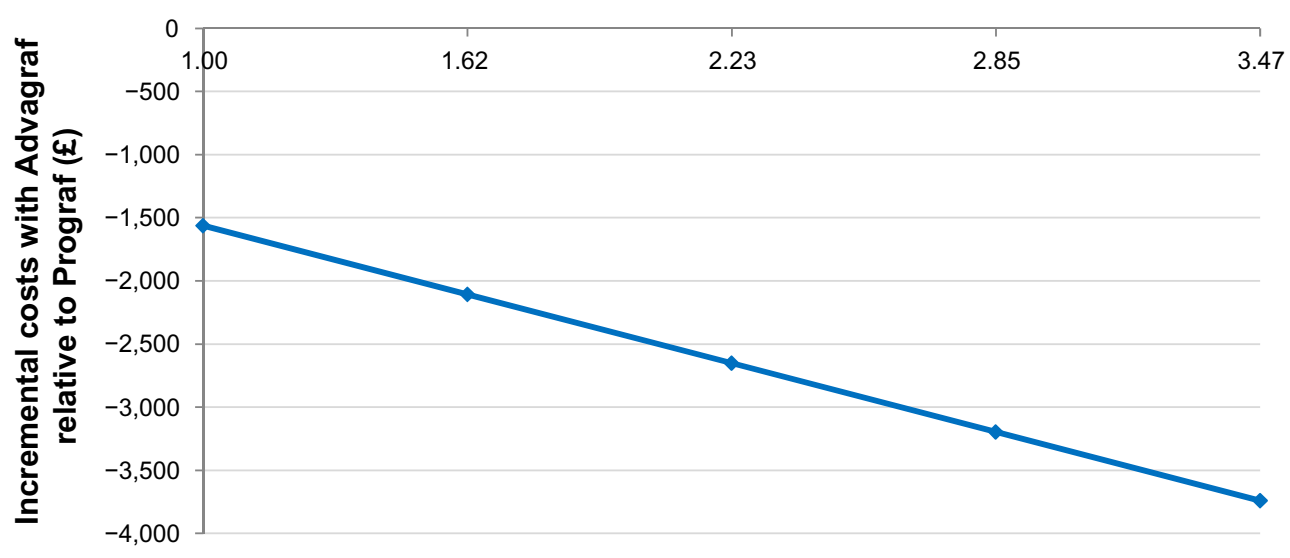

Relative risk of graft failure with nonadherence

Figure 2 Incremental cost of Advagraf relative to Prograf over a range of relative risks of graft failure with poor adherence.

\section{Discussion}

The present study showed that, relative to an immediaterelease tacrolimus formulation, using a prolonged-release formulation in renal transplant patients could result in substantial cost savings in the UK setting over 5 years. The strengths of the present analysis lie in its transparent modeling approach, use of recent, robust, and UK-specific data to model graft survival and mortality, and the use of up-to-date UK cost data and resource-use assumptions. However, as with any modeling analysis, there are a number of caveats that should be noted when interpreting the results. In particular, while the underlying clinical data might not be anticipated to vary considerably between health care settings in which the standard of care is comparable to the UK, the adopted perspective of a UK health care payer necessarily focused the analysis on UK-specific economic data. For instance, the present analysis used cost data from the BNF and NHS National Tariff, and did not capture any traits of health care-financing systems, such as patient copay, that are not applicable in the UK setting.

Despite the use of data primarily from the UK setting, there was some unavoidable heterogeneity in the data sources used. For instance, two distinct data sources were used to capture differences in the incidence of graft failure based on adherence. The proportion of patients adherent to their tacrolimus regimen was taken from a study published by Kuypers et al, which reported the findings of a randomized clinical trial investigating adherence in renal transplant recipients on once- versus twice-daily tacrolimus conducted in Belgium in 2008-2009. ${ }^{11}$ As the analysis focused on patient adherence and persistence to the treatment regimen, end points such as the incidence of acute rejection or graft loss were not reported, and the link between nonadherence and increased incidence of graft loss therefore relied on data from a previous study, specifically a 2004 meta-analysis by Butler et al. ${ }^{15}$ The Butler analysis was chosen because it represents the findings of a systematic literature review and meta-analysis focused specifically on the relationship between adherence and graft loss in renal transplant recipients. And while it should be noted that the majority of patients were taking either cyclosporine or azathioprine as their primary immunosuppressive medication, a recent study conducted by Wiebe et al (in which the majority of the patients were on tacrolimus), reported similar associations between nonadherence and poor outcomes. ${ }^{34}$ The effect of this was explored in a series of sensitivity analyses, including investigating the effect of equivalent adherence in both arms and setting the relative risk of graft failure with nonadherence to 1 . None of these analyses changed the cost-saving outcome of Advagraf relative to Prograf (although the magnitude of the savings was reduced).

The proportion of patients adherent to treatment with once- versus twice-daily immunosuppressive regimens was a key driver of the modeling analysis. Data used in the present analysis from the Kuypers et al study were recently corroborated by a prospective observational study reported by Sabbatini et al. ${ }^{35}$ In the study, the adherence status of 310 stable renal transplant recipients on twice-daily immunosuppressive medication was assessed at baseline. A group of 121 patients was then switched to a once-daily tacrolimus regimen and followed for 6 months. At baseline, $23.5 \%$ of all patients were nonadherent, compared with $21.2 \%$ of patients on twice-daily tacrolimus in the Kuypers et al study. After 6 months, the proportion of nonadherent patients remained unchanged in the twice-daily control group (from 45 patients of 189 at baseline to 44 after 6 months), but improved in 
$36 \%$ of patients in the switch group, leaving just 18 of $121(14.9 \%)$ patients nonadherent to once-daily immunosuppressive therapy ( $P<0.05$ when compared with baseline). This compares with nonadherence in $11.8 \%$ of patients in the once-daily arm of the present analysis..$^{35}$ The remaining nonadherence in both the Sabbatini et al and Kuypers et al studies may result from either the residual pill burden in the once-daily arm (reported as 10.7 pills per day in the Sabbatini study) or from intentional nonadherence, which was reported in $13.8 \%$ of patients in a 2012 study by Griva et al. ${ }^{36}$ Griva et al emphasized the importance of supporting all patients by establishing medication routines, and foreseeing and addressing likely disruptions to the prescribed regimen. Such support should therefore be provided alongside initiation of once-daily tacrolimus to optimize adherence, particularly in intentionally nonadherent patients.

One potential shortcoming of the present analysis centers around the limited outcomes captured. For instance, Pinsky et al reported significant variations in the incidence of mortality up to 3 years after transplant, across patients divided into quartiles by first-year adherence to their immunosuppressive regimen. ${ }^{13}$ In the study, patient mortality in the "excellent" adherence group was 3.0\% compared with $5.4 \%$ in the "fair" compliance group $(P<0.0001) .{ }^{13}$ Despite this evidence, the present analysis assumed no difference in mortality either between Prograf and Advagraf or between adherent and nonadherent patients. The primary justification for this was the implication of capturing mortality in a budget-impact model, namely that a comparator associated with an increased risk of mortality would appear to be cheaper, while the reduction in life expectancy would not be captured in the model. Cost-effectiveness analyses, in which incremental costs are balanced with incremental effectiveness outcomes (such as life expectancy), are better suited to capturing differences in mortality.

As discussed, the findings of the present study rest on the two key assumptions that once-daily dosing improves adherence relative to twice-daily dosing, and that improved adherence in turn leads to reduced incidence of graft loss. These assumptions are backed by numerous published trials, meta-analyses, and reviews, ${ }^{6,9-15}$ but data have only recently been published that explore the underlying mechanisms of graft failure in nonadherent patients. ${ }^{33}$ In 2012, Sellarés et al published the findings of a prospective study in 315 kidneyallograft recipients, in which cause was attributed to graft failure based on biopsy diagnoses, clinical information, clinicians' concerns about nonadherence, and antibody data. ${ }^{33}$ The study reported 60 graft failures in total, 19 (73.1\%) of which occurred in the group of 26 patients in which concerns about nonadherence had been reported. This compared with 41 graft failures in the 289 remaining patients (14.2\%), providing another demonstration of the increased risk of graft failure in nonadherent patients. Donor-specific antibodies (DSAs; $n=16$ ) or antibodies against human leukocyte antigen without identified DSAs $(n=2)$ were present in all nonadherent patients who experienced a graft failure due to rejection ( $n=18$, including one patient with missing data), suggesting that antibody-mediated rejection (as opposed to T-cell-mediated rejection) is a contributing factor to graft failure in nonadherent patients. There are no proven effective therapies for the treatment of DSA-positive patients with allograft dysfunction. Currently, costly therapies, such as intravenous immunoglobulin and rituximab (£13,573 per rejection episode), eculizumab ( $£ 37,800$ for 6 weeks at $600 \mathrm{mg} /$ week), and plasmapheresis are used, but with little supportive data. ${ }^{37-41}$ Such therapies may also carry a substantial risk of adverse events. Further health care-cost implications to be considered for patients with DSAs include increased clinic visits, more diagnostics (DSA measurement with flow cytometer and kidney biopsies), and hospitalization for procedures and treatments. The frequency with which DSAs are implicated in graft failure attributed to nonadherence suggests that the present analysis may be conservative in its assumptions on the cost of graft failure. ${ }^{42}$ As noted by the authors of the Sellarés et al study, further prospective studies of nonadherence that include social, behavioral, and financial issues would make a useful addition to the body of evidence on the mechanisms and outcomes associated with nonadherence. ${ }^{33}$

In conclusion, the present study shows that Advagraf is cost saving relative to Prograf in renal transplant recipients in the UK setting, with savings being driven primarily by reduced costs associated with dialysis after graft failure. As previous studies have shown Advagraf to have a well-characterized efficacy and safety profile in the prophylaxis of graft rejection, this study provides evidence that it may also result in substantial cost savings in the UK setting. These data, combined with the previously reported patient preference for once-daily over twice-daily immunosuppressive medication, ${ }^{43}$ suggest that Advagraf is not only preferred by patients but is also a clinically and economically appropriate choice for immunosuppression in renal transplant recipients in the UK.

\section{Acknowledgment}

This study was funded by Astellas Pharma Europe, Chertsey, UK. 


\section{Disclosure}

Gorden Muduma and Isaac Odeyemi are full-time employees of Astellas Pharma Europe. Richard F Pollock and Jayne Smith-Palmer are full-time employees of Ossian Health Economics and Communications $\mathrm{GmbH}$, which received consultancy fees from Astellas Pharma Europe to perform the modeling analysis and prepare the manuscript.

\section{References}

1. European Medicines Agency. Advagraf European public assessment report annex I: summary of product characteristics. Available from: http://www.ema.europa.eu/docs/en_GB/document_library/EPAR_-Product_Information/human/000712/WC500022234.pdf. Accessed June 4, 2013.

2. US Food and Drug Administration. Drug approval package: Prograf (tacrolimus) injection. 2003. Available from: http://www.accessdata. fda.gov/drugsatfda_docs/nda/pre96/050708_prograf_toc.cfm. Accessed June 4, 2013.

3. Staatz CE, Tett SE. Clinical pharmacokinetics and pharmacodynamics of tacrolimus in solid organ transplantation. Clin Pharmacokinet. 2004;43(10):623-653.

4. Dew MA, DiMartini AF, De Vito Dabbs A, et al. Rates and risk factors for nonadherence to the medical regimen after adult solid organ transplantation. Transplantation. 2007;83(7):858-873.

5. Dharancy S, Giral M, Tetaz R, Fatras M, Dubel L, Pageaux GP. Adherence with immunosuppressive treatment after transplantation: results from the French trial PREDICT. Clin Transplant. 2012;26(3): E293-E299.

6. Weng FL, Israni AK, Joffe MM, et al. Race and electronically measured adherence to immunosuppressive medications after deceased donor renal transplantation. J Am Soc Nephrol. 2005;16(6): 1839-1848.

7. National Health Service Business Services Authority. Prescription cost analysis (PCA) data. 2013. Available from: http://www.nhsbsa.nhs.uk/ PrescriptionServices/3494.aspx. Accessed July 31, 2013.

8. European Medicines Agency. European public assessment report: Advagraf - summary for the public. 2008. Available from: http://www. emea.europa.eu/docs/en_GB/document_library/EPAR_-_Summary_ for_the_public/human/000712/WC500022235.pdf. Accessed June 4, 2013.

9. Saini SD, Schoenfeld P, Kaulback K, Dubinsky MC. Effect of medication dosing frequency on adherence in chronic diseases. Am J Manag Care. 2009;15(6):e22-e33.

10. Claxton AJ, Cramer J, Pierce C. A systematic review of the associations between dose regimens and medication compliance. Clin Ther. 2001;23(8):1296-1310.

11. Kuypers DR, Peeters PC, Sennesael JJ, et al. Improved adherence to tacrolimus once-daily formulation in renal recipients: a randomized controlled trial using electronic monitoring. Transplantation. 2013;95(2): 333-340.

12. Dobbels F, Ruppar T, De Geest S, Decorte A, Van Damme-Lombaerts R, Fine RN. Adherence to the immunosuppressive regimen in pediatric kidney transplant recipients: a systematic review. Pediatr Transplant. 2010;14(5):603-613.

13. Pinsky BW, Takemoto SK, Lentine KL, Burroughs TE, Schnitzler MA, Salvalaggio PR. Transplant outcomes and economic costs associated with patient noncompliance to immunosuppression. Am J Transplant. 2009;9(11):2597-2606.

14. Spivey CA, Chisholm-Burns MA, Damadzadeh B, Billheimer D. Determining the effect of immunosuppressant adherence on graft failure risk among renal transplant recipients. Clin Transplant. 2014;28(1): 96-104.
15. Butler JA, Roderick P, Mullee M, Mason JC, Peveler RC. Frequency and impact of nonadherence to immunosuppressants after renal transplantation: a systematic review. Transplantation. 2004;77(5):769-776.

16. NHS Blood and Transplant. Transplant activity in the UK. Activity report 2011-12. Available from: http://www.organdonation.nhs.uk/ statistics/transplant_activity_report/archive_activity_reports/pdf/ukt/ activity_report_2011_12.pdf. Accessed March 3, 2014.

17. McEwan P, Dixon S, Baboolal K, Conway P, Currie CJ. Evaluation of the cost effectiveness of sirolimus versus tacrolimus for immunosuppression following renal transplantation in the UK. Pharmacoeconomics. 2006;24(1):67-79.

18. Krämer BK, Charpentier B, Bäckman L, et al. Tacrolimus once daily (Advagraf) versus twice daily (Prograf) in de novo renal transplantation: a randomized phase III study. Am J Transplant. 2010;10(12): 2632-2643.

19. Zhang J, Yu KF. What's the relative risk? A method of correcting the odds ratio in cohort studies of common outcomes. JAMA. 1998;280(19):1690-1691

20. National Institute for Health and Care Excellence. CG125: peritoneal dialysis - NICE guideline. 2012. Available from: http://guidance.nice. org.uk/CG125/NICEGuidance/pdf/English. Accessed June 4, 2013.

21. Renal Association. Haemodialysis. Available from: http://www.renal.org/ clinical/guidelinessection/haemodialysis.aspx. Accessed June 4, 2013.

22. Joint Formulary Committee. British National Formulary online. London: BMJ Group and Pharmaceutical Press. §8.2.2 Corticosteroids and other immunosuppressants: Tacrolimus (Advagraf). March 2013. Available from: http://www.medicinescomplete.com/mc/bnf/current/PHP5647advagraf.htm. (Registration required) Accessed August 20, 2013.

23. Joint Formulary Committee. British National Formulary online. London: BMJ Group and Pharmaceutical Press. §8.2.2 Corticosteroids and other immunosuppressants: Tacrolimus (Prograf). March 2013. Available from: http://www.medicinescomplete.com/mc/bnf/current/PHP5643-prograf. htm. (Registration required) Accessed August 20, 2013.

24. Joint Formulary Committee. British National Formulary online. London: BMJ Group and Pharmaceutical Press. §8.2.2 Corticosteroids and other immunosuppressants: Tacrolimus (Adoport). March 2013. Available from: http://www.medicinescomplete.com/mc/bnf/current/PHP5643-prograf. htm. (Registration required) Accessed August 20, 2013.

25. Joint Formulary Committee. British National Formulary online. London: BMJ Group and Pharmaceutical Press. §8.2.1 Antiproliferative immunosuppressants: Mycophenolate mofetil. March 2013. Available from: http:// www.medicinescomplete.com/mc/bnf/current/PHP5609-mycophenolatemofetil-non-proprietary.htm. (Registration required) Accessed August 20, 2013.

26. Joint Formulary Committee. British National Formulary online. London: BMJ Group and Pharmaceutical Press. §6.3.2 Glucocorticoid therapy: Betamethasone. March 2013. Available from: http://www.medicinescomplete.com/mc/bnf/current/PHP18872-betamethasone-non-proprietary. htm. (Registration required) Accessed August 20, 2013.

27. Joint Formulary Committee. British National Formulary online. London: BMJ Group and Pharmaceutical Press. §6.3.2 Glucocorticoid therapy: Methylprednisolone. March 2013. Available from: http://www. medicinescomplete.com/mc/bnf/current/PHP4373-solu-medrone.htm. (Registration required) Accessed August 20, 2013.

28. Joint Formulary Committee. British National Formulary online. London: BMJ Group and Pharmaceutical Press. \$8.2.2 Corticosteroids and other immunosuppressants: Antithymocyte immunoglobulin (rabbit). March 2013. Available from: http://www.medicinescomplete.com/mc/bnf/current/PHP5620-antithymocyte-immunoglobulin-rabbit.htm. (Registration required) Accessed August 20, 2013.

29. National Health Service. National Tariff 2012-13. Available from: https:// www.gov.uk/government/uploads/system/uploads/attachment_data/ file/216214/dh_133578.xls. Accessed August 20, 2013.

30. Mauskopf JA, Sullivan SD, Annemans L, et al. Principles of good practice for budget impact analysis: report of the ISPOR Task Force on good research practices - budget impact analysis. Value Health. 2007;10(5):336-347. 
31. National Institute for Health and Clinical Excellence. Guide to the methods of technology appraisal. 2008. Available from: http://www. nice.org.uk/media/B52/A7/TAMethodsGuideUpdatedJune2008.pdf. Accessed June 4, 2013.

32. Beaudet A, Palmer JL, Timlin L, et al. Cost-utility of exenatide once weekly compared with insulin glargine in patients with type 2 diabetes in the UK. J Med Econ. 2011;14(3):357-366.

33. Sellarés J, de Freitas DG, Mengel M, et al. Understanding the causes of kidney transplant failure: the dominant role of antibodymediated rejection and nonadherence. Am J Transplant. 2012;12(2): 388-399.

34. Wiebe C, Gibson IW, Blydt-Hansen TD, et al. Evolution and clinical pathologic correlations of de novo donor-specific HLA antibody post kidney transplant. Am J Transplant. 2012;12(5):1157-1167.

35. Sabbatini M, Garofalo G, Borrelli S, et al. Efficacy of a reduced pill burden on therapeutic adherence to calcineurin inhibitors in renal transplant recipients: an observational study. Patient Prefer Adherence. 2014;8:73-81.

36. Griva K, Davenport A, Harrison M, Newman SP. Non-adherence to immunosuppressive medications in kidney transplantation: intent vs forgetfulness and clinical markers of medication intake. Ann Behav Med. 2012;44(1):85-93.
37. Vo AA, Peng A, Toyoda M, et al. Use of intravenous immune globulin and rituximab for desensitization of highly HLA-sensitized patients awaiting kidney transplantation. Transplantation. 2010;89(9):1095-1102.

38. National Health Service. Third National Immunoglobulin Database Report. London NHS; 2012.

39. Joint Formulary Committee. British National Formulary online. London: BMJ Group and Pharmaceutical Press. MabThera. Available from: http://www.medicinescomplete.com/mc/bnf/current/PHP5664mabthera.htm. (Registration required) Accessed September 20, 2013.

40. Galliford J, Lawrence C, Chan K, et al. Eculizumab reverses resistant acute Antibody Mediated Rejection and prevents allograft loss. Poster presented at: 14th Annual Congress of the British Transplantation Society; March 9-11, 2011; Bournemouth, UK.

41. Joint Formulary Committee. British National Formulary online. London: BMJ Group and Pharmaceutical Press. Soliris. Available from: http:// www.medicinescomplete.com/mc/bnf/current/PHP5923-soliris.htm. (Regsitration required) Accessed September 18, 2013.

42. Puttarajappa C, Shapiro R, Tan HP. Antibody-mediated rejection in kidney transplantation: a review. J Transplant. 2012;2012:193724.

43. Guirado L, Cantarell C, Franco A, et al. Efficacy and safety of conversion from twice-daily to once-daily tacrolimus in a large cohort of stable kidney transplant recipients. Am J Transplant. 2011;11(9):1965-1971.
Patient Preference and Adherence

\section{Publish your work in this journal}

Patient Preference and Adherence is an international, peer-reviewed, open access journal focusing on the growing importance of patient preference and adherence throughout the therapeutic continuum. Patient satisfaction, acceptability, quality of life, compliance, persistence and their role in developing new therapeutic modalities and compounds to

\section{Dovepress}

optimize clinical outcomes for existing disease states are major areas of interest. This journal has been accepted for indexing on PubMed Central. The manuscript management system is completely online and includes a very quick and fair peer-review system. Visit http://www.dovepress.com/ testimonials.php to read real quotes from published authors. 